\title{
Best Level of Parameters for a Critical Buckling Load for Circular Thin- Walled Structure Subjected to Bending
}

\author{
Hussein M. H. Al-Khafaji \\ Department of Mechanical Engineering/University of Technology/Baghdad \\ Email: hussalkhafaji@gmail.com
}

(Received 22 February 2017; accepted 2 July 2017)

https://doi.org/10.22153/kej.2017.07.003

\begin{abstract}
Circular thin walled structures have wide range of applications. This type of structure is generally exposed to different types of loads, but one of the most important types is a buckling. In this work, the phenomena of buckling was studied by using finite element analysis. The circular thin walled structure in this study is constructed from; cylindrical thin shell strengthen by longitudinal stringers, subjected to pure bending in one plane. In addition, Taguchi method was used to identify the optimum combination set of parameters for enhancement of the critical buckling load value, as well as to investigate the most effective parameter. The parameters that have been analyzed were; cylinder shell thickness, shape of stiffeners section and the number of stiffeners. Furthermore, to verify the contribution of parameters on buckling response, the analysis of variance technique (ANOVA) method was implemented, which gave the contribution weight as percentages. The analysis of results by these two methods showed that the more effective parameter on the critical buckling load was the thickness of cylinder's shell and the lowest effective was the number of stiffeners The values of parameters that gave the best critical buckling load combination were: 1) the ratio of cylinder's diameter to thickness of its shell was 133,2$)$ the ratio of the depth to thickness of stiffeners was1.6, and 3) the number of stiffeners was 12.
\end{abstract}

Keywords: buckling, FEM, Taguchi method, thin walled structure and ANOVA.

\section{Introduction}

Circular hollow sections thin-walled structure have a wide use in many applications such as; aircraft lightweight aerospace, towers of wind turbines, chimneys, marine structure, and etc...[1]. One of the important phenomena for failure and collapse of this type of structure is the local buckling. this phenomenon caused by presenting of compression and shear forces resulting from applying of one or combined of pure axial compression, torsion, and bending loads. Thus, it is desirable to know what are the circumstances that lead to buckle this type of thin-walled structures, what is the best design to reduce or avoid occurring of buckling and how to improve the stability characteristics. Many type of strengthening were used to reinforce the thin wall structure with circular cross section, but the most common are the longitudinal (stringers) and circumferential (rings). The following works [2], [3], [4], and [5]; were investigated theoretically and experimentally these two types of stiffening, the analysis included the shape, size and the enhancement of critical buckling stresses with different kinds of load. [6], [7], and [8] investigated the effect of opening and cutout presenting in the circular thin walled structures on the buckling behavior, and how to stiffen these opening.

As well as, unstiffened circular thin walled structures were considered in the researches. 
Reddy [9] tests unstiffened cylindrical tubes under pure bending experimentally to estimate the relation between the radius to thickness $(\mathrm{r} / \mathrm{t})$ and strain, also to observe the modes of deformation. It is observed that a small change in circular cross section to the oval shape, does not causes the ripples initiation which is the first cause of collapse. The Author used in test radius to thickness ratio (r/t) range (15-40) with nominal diameter $25 \mathrm{~mm}$ and $600 \mathrm{~mm}$ long with two materials aluminum alloy and stainless steel. Jiao and others [1] and [10] studied the bending capacity and buckling behavior of stiffened and unstiffened circular-section structures with different diameter to thickness ratio (17-300), subjected to more than one type of loading and supporting.

The finite elements method represents one of various theoretical methods applied to study the circular thin wall structure, the researcher Khonke and Schnobrich [11] used finite element method to analyze the stresses on a circular cylindrical shell, which was reinforced by using eccentrically ribs strengthen longitudinally and peripherally. They prove that the finite element method can be an effective method to simulate the thin walled structure. E. Kim and S. Kim [12] conducted analysis for buckling to cylindrical shells with diameter to thickness ratio of more than 800 , to evaluate the buckling strength, finite element analysis was used. In addition, the researchers in [13],[14],[15], [16] and [17], have used finite element to investigate stability behavior, optimization and design of unstiffened and stiffened circular thin walled structures.

Khamlichi et al. [18] and [19] showed that there is a further decreasing in the critical stress of compressed circular cylindrical shells with increasing one extra defect, a finite element method was used to model and simulate the problem. The model consists of circular cylindrical shell with two triangular defects, a parametric study (Taguchi method) applied to regard the initial geometric influence of these two defects.

In this work, a finite element analysis using software ANSYS was applied to model the effect of geometry and cross section on the linear buckling behavior of circular thin wall structure (CTWS). CTWS is strengthen with longitudinal stringers. Furthermore, the Taguchi method was applied to explore the effectiveness of geometrical parameters and their combine sets on the strength of buckling. Moreover, the analysis of variance technique (ANOVA) was employed to determine the weight and contribution of each parameters on the critical load of buckling.

\section{Theory}

\subsection{Buckling and Finite Element}

The Buckling is a state of structure in which the applied load are large enough to disturb or destroy the stability of structure. The linear buckling analysis predicts the theoretical buckling strength of a structure. It is modeled as an eigenvalue equation [15], [20] and [21]:

$$
\left(K+\lambda K_{\sigma}\right) \psi=0
$$

Where $\mathrm{K}$ is stiffness matrix, $\boldsymbol{K}_{\sigma}$ is stress stiffness matrix, $\lambda$ is the eigenvalue (load factor) and $\psi$ is the eigenvector of displacements. The solutions for above formula are the eigenvalues and corresponding eigenvectors. The smallest value from the eigenvalues (roots) represents the critical load factor of buckling. If the applied load is $\mathrm{F}$ then the critical load will be $\left(\lambda^{*} \mathrm{~F}\right)$. If the load is only bending, and cross section of structure is symmetric, there will be positive $\lambda$ (load factors) and other with negative sign but equal in absolute value, therefore, it should be take the critical load factor according to the direction of applied load.

\subsection{Taguchi}

Genichi Taguchi founded the Taguchi method in 1949. It is a methodology for getting the relationship between the input process and output of products. It depends on using orthogonal array (OA) with a small number of experiments to acquire the most favorable setting of parameters for process The Taguchi method is an useful tool for better design, gathering concept of quality loss function and design of experiment theory. It provides a systematically approach for optimizing the design performance, cost, and quality. This method employs a statistical measurement named as the ratio of the mean (called signal) to the standard deviation (called noise) $(\mathrm{S} / \mathrm{N})$, which represents a logarithmic function of wanted output. There are three standard types of $\mathrm{S} / \mathrm{N}$ ratio; higher the better (HB), lower the better (LB) and Nominal the best (NB) [22] and [23]. In this study, the higher critical load of buckling is required, therefore, the higher the better formula is used:

$S / N=-10 \log \left(\frac{1}{n} \sum_{i=1}^{n} \frac{1}{y^{2}}\right)$

Where:

$\mathrm{y}$ : is the read data.

$\mathrm{n}$ : is the number of observations. 


\subsection{Analysis of Variance (ANOVA)}

Analysis of variance (ANOVA) is a powerful statistical technique, which specify the important parameters and demonstrate the percentage contribution of each parameter.

In this research, the ratio $(\mathrm{S} / \mathrm{N})$ was used for making the decision.

The technique of ANOVA is based on the total sum of squared deviations $\left(S S_{T}\right)$ which is equal [24] and [22]:

$S S_{T}=\sum_{i=1}^{n}\left(n_{i}-n_{m}\right)^{2}$

The percentage contribution $\mathrm{P}$ could be calculate as:

$P=\frac{S s_{\mathbb{d}}}{S s_{T}}$

d.o.f of any parameter(factor) $=\mathrm{k}-1$

Total d.o.f $=\mathrm{n}-1$

$d_{1} o_{2}$ f of error $=$ total d, of $-\sum d_{1} a_{2} f$ of paprometers

$V=\frac{s s_{d}}{d . a_{f} f}$

$F=\frac{V}{v_{E}}$

Where:

$\mathrm{N}$ the number of observation (trails) in the orthogonal array.

$n_{i} \quad$ mean $\mathrm{S} / \mathrm{N}$ ratio for the ith observation.

$n_{m}$ mean of all parameters.

$\mathrm{SS}_{\mathrm{d}}$ sum of the squared deviations.

$\mathrm{K}$ amount of levels for each parameter.

$\mathrm{P}$ contribution's percentage.

$\mathrm{V}$ parameter's (factor) variance.

$V_{E}$ error's variance.

d.o.f degree of freedom.

F F- test, which is indicator quality characteristic of process.

\section{Modeling}

\subsection{Structure Modeling}

The model of the structure consists of cylindrical thin wall (CTWS) cantilever beam structure. Two plates were mounted at terminal ends of the beam; to prevent ovalization. One of the plate to support the beam (fixed end) and the other at the free end of beam to support the applied load. The dimensions of plates at the fixed end edge and at free end are $(560 \times 560 \times 20) \mathrm{mm}$ and $(560 \times 560 \times 10) \mathrm{mm}$, respectively, as shown in

Fig. 1. The length of beam (bay between the two plates at the ends) was designed according to the ratio between plates-spacing $(l)$ and radius (r) which is more than $[(l / r)>(1 / 2)]$ to reduce the strength gain of beam [2] and [25]. Accordingly, $(l)$ and $(r)$ were set as $2000 \mathrm{~mm}$ and $200 \mathrm{~mm}$, respectively. The diameter to thickness ratio of CTWS (D/t) was taken in different values by changing thickness and keeping diameter constant at $(\mathrm{D}=400 \mathrm{~mm})$. The thickness $\mathrm{t}$ varies in three values $(1,2$, and 3$) \mathrm{mm}$. The structure is strengthened with three different shape and three different numbers of longitudinal stringers. The shape of strangers have been chosen as a rectangular cross section with three different dimensions having the same area to keep the same mass, as shown in

Fig. 2. These stringers were connected longitudinally along one side (connected rigidly) to the shell of the CTWS, and they are not supported at their transversal two ends (the two ends free).

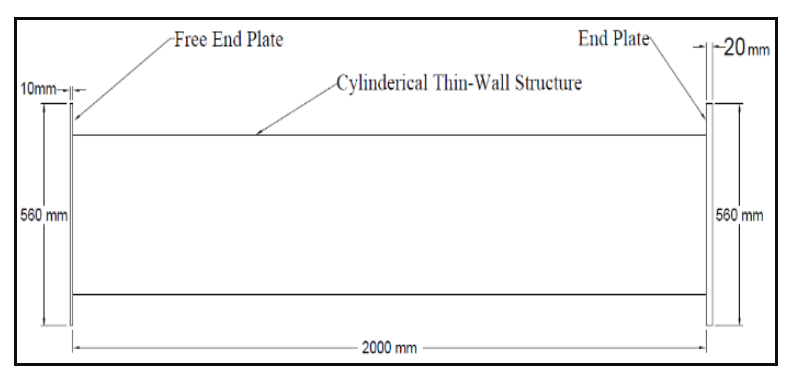

Fig. 1. The cylindrical thin wall structure

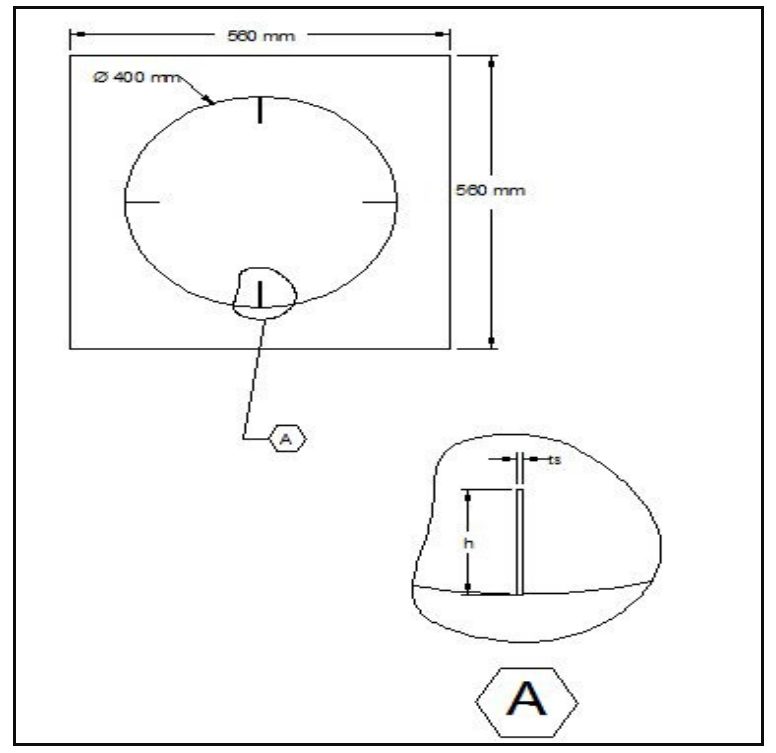

Fig. 2. the detail of stiffener. 
The chosen parameters for analysis are three, namely: diameter to thickness of the cylindrical shell $(\mathrm{D} / \mathrm{t})$, the Number of stringer $\left(\mathrm{N}_{\mathrm{s}}\right)$, and the ratio of depth to thickness of stringer $\left(\mathrm{h} / \mathrm{t}_{\mathrm{s}}\right)$. Each one of these parameters have three levels as shown in table 1.

Table 1,

Parameters and levels

\begin{tabular}{lllll}
\hline symbols & parameter & $\begin{array}{l}\text { levels } \\
\text { Level }\end{array}$ & $\begin{array}{l}\text { Level } \\
\mathbf{1}\end{array}$ & $\begin{array}{l}\mathbf{2} \\
\text { Level }\end{array}$ \\
\hline $\mathrm{A}$ & $\mathrm{N}_{\mathrm{s}}$ & 4 & 8 & 12 \\
$\mathrm{~B}$ & $\mathrm{~h} / \mathrm{t}_{\mathrm{s}}$ & 25 & 6.25 & 1.6 \\
$\mathrm{C}$ & $\mathrm{D} / \mathrm{t}$ & 400 & 200 & 133 \\
\hline
\end{tabular}

Where the values of Fig 2:

$\mathrm{N}_{\mathrm{s}} \quad$ No. of stiffeners

h $(\mathrm{mm})$ depth of stringer $(50,25,12.5)$.

$t_{\mathrm{s}}(\mathrm{mm})$ thickness of stringer $(2,4,8)$.

$\mathrm{D}(\mathrm{mm})$ diameter of cylinder (400).

$\mathrm{t}(\mathrm{mm})$ thickness of cylinder $(1,2,3)$.

\subsection{Finite Element Modeling}

The finite element software that used to perform analysis is ANSYS 16. Shell281- element was used to create mesh. This element has eight nodes. Each node has six degrees of freedom: rotations about the $\mathrm{x}, \mathrm{y}$, and $\mathrm{z}$-axes, and translations in the $\mathrm{x}, \mathrm{y}$, and $\mathrm{z}$-axes, and is suitable for thin and moderately thick structures [26]. To generate the mesh, the chosen elements size were; $10 \mathrm{~mm}$ in the axial, and circumferential directions for CTWS. The element size for the end-plates were $28 \mathrm{~mm}$. Depending on the dimension of stiffener; the element size for depth ranges from 3 to $5 \mathrm{~mm}$, while in the axial direction is $10 \mathrm{~mm}$. The fixed end of structure is supported by eight point on the end plate to simulate the connection by eight bolts. The load is applied on the free end in the middle of one edge of plate, as shown in the Fig 3.

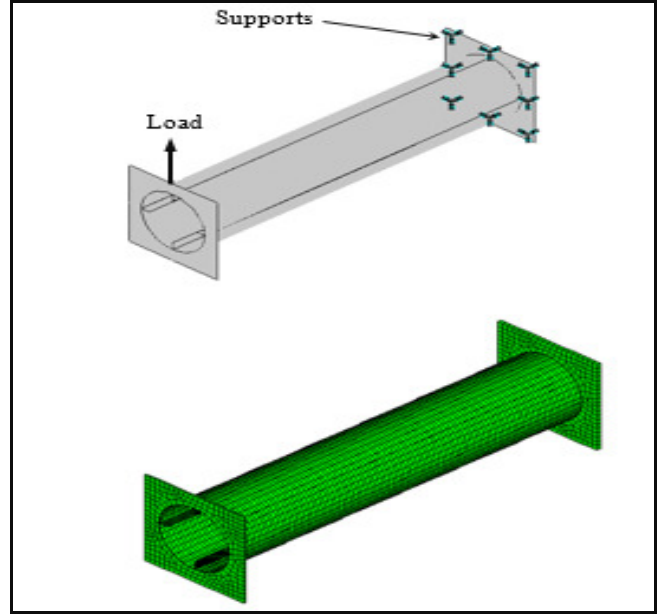

Fig. 3. Finite elements model

The steel structure material was implemented, which is considered as a linear isotropic material. Table 2 lists the properties of used material.

Table 2,

Steel structure material properties

\begin{tabular}{llll}
\hline $\begin{array}{l}\text { Young's } \\
\text { modulus } \\
\text { (MP) }\end{array}$ & $\begin{array}{l}\text { Poisson's } \\
\text { ratio }\end{array}$ & $\begin{array}{l}\text { tensile } \\
\text { yield } \\
\text { strength } \\
\text { (MP) }\end{array}$ & $\begin{array}{l}\text { tensile } \\
\text { ultimate } \\
\text { strength } \\
\text { (MP) }\end{array}$ \\
\hline $2 \times 10^{5}$ & 0.3 & 250 & 460 \\
\hline
\end{tabular}

\section{Result and Dissection}

\subsection{Finite Element Results}

A linear buckling analysis is performed to calculate the critical load buckling. According to three parameters and three levels its need an orthogonal array L27. Thus, twenty-seven value of critical load were found from different combinations of levels and parameters.

Table 3 shows the levels combinations and the corresponding results of loads buckling. Each value of critical buckling load in the fifth column of Table 3 is obtained from the calculating of average value for analyzing the finite elements model to three times for each parameters set and corresponding levels (raw in the table). 
Table 3,

Paramters and resulting critical buckling load

\begin{tabular}{|c|c|c|c|c|}
\hline $\begin{array}{l}\text { No. } \\
\text { of } \\
\text { tests }\end{array}$ & $\begin{array}{l}\text { No. of } \\
\text { Stiffeners } \\
\left(\mathbf{N}_{s}\right)\end{array}$ & $\begin{array}{l}\text { shape of } \\
\text { stiffeners } \\
(\mathbf{h} / \mathbf{t s})\end{array}$ & $D / t$ & $\begin{array}{l}\text { Critical } \\
\text { Buckling } \\
\text { Load (MN) }\end{array}$ \\
\hline 1 & 4 & 25 & 400 & 34.52 \\
\hline 2 & 8 & 25 & 400 & 37.78 \\
\hline 3 & 12 & 25 & 400 & 40.28 \\
\hline 4 & 4 & 6.25 & 400 & 42.72 \\
\hline 5 & 8 & 6.25 & 400 & 44.78 \\
\hline 6 & 12 & 6.25 & 400 & 49.82 \\
\hline 7 & 4 & 1.6 & 400 & 45.28 \\
\hline 8 & 8 & 1.6 & 400 & 48.55 \\
\hline 9 & 12 & 1.6 & 400 & 50.37 \\
\hline 10 & 4 & 25 & 200 & 76.63 \\
\hline 11 & 8 & 25 & 200 & 77.86 \\
\hline 12 & 12 & 25 & 200 & 80.22 \\
\hline 13 & 4 & 6.25 & 200 & 137.58 \\
\hline 14 & 8 & 6.25 & 200 & 140.79 \\
\hline 15 & 12 & 6.25 & 200 & 159.83 \\
\hline 16 & 4 & 1.6 & 200 & 147.53 \\
\hline 17 & 8 & 1.6 & 200 & 150.01 \\
\hline 18 & 12 & 1.6 & 200 & 161.51 \\
\hline 19 & 4 & 25 & 133 & 113.51 \\
\hline 20 & 8 & 25 & 133 & 115.18 \\
\hline 21 & 12 & 25 & 133 & 118.06 \\
\hline 22 & 4 & 6.25 & 133 & 319.47 \\
\hline 23 & 8 & 6.25 & 133 & 327.52 \\
\hline 24 & 12 & 6.25 & 133 & 334.82 \\
\hline 25 & 4 & 1.6 & 133 & 332.11 \\
\hline 26 & 8 & 1.6 & 133 & 339.27 \\
\hline 27 & 12 & 1.6 & 133 & 343.14 \\
\hline
\end{tabular}

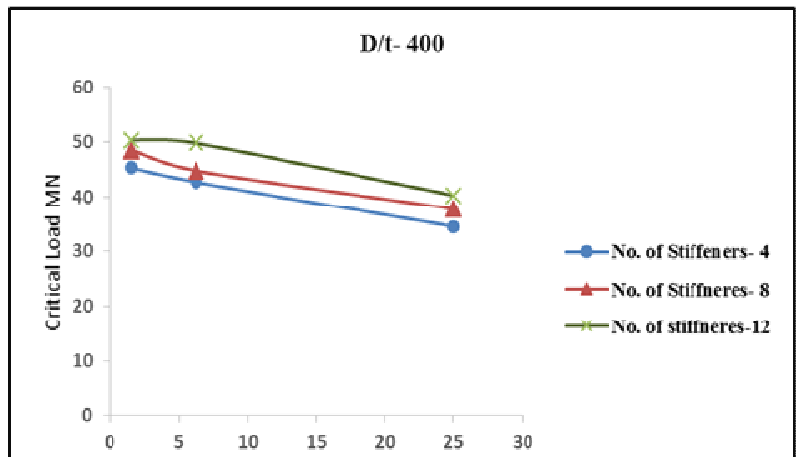

The Fig. 4 and Fig. 5 shows the variation of load with variation in two parameters and the third one is constant. These figures show that the most effective parameter is the thickness of cylinder especially in the Fig. 5, while the less effective parameter is the Number of stiffeners; this is attributed to the load, which is applied in one plane (vertical plane) as shown in Fig 3. 

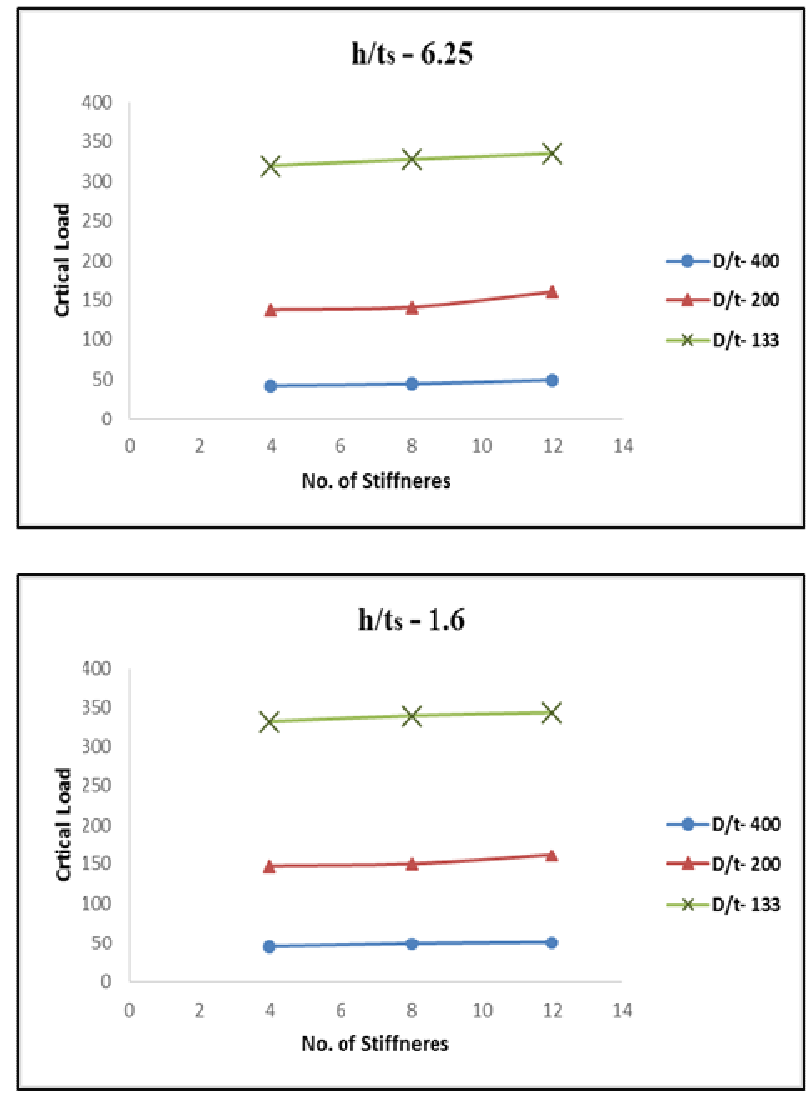

Fig. 5. The variation of critical load with parameters at constant $h / t$ s ratio

Fig.7 shows samples of local buckling deformation in cylinder shell and stiffeners. The buckling occurs in the side of compression stress due to bending. it could be seen that mode of the buckling where the cylinder's shell of structure is wrinkled, and the stiffener buckled in sine wave manner.
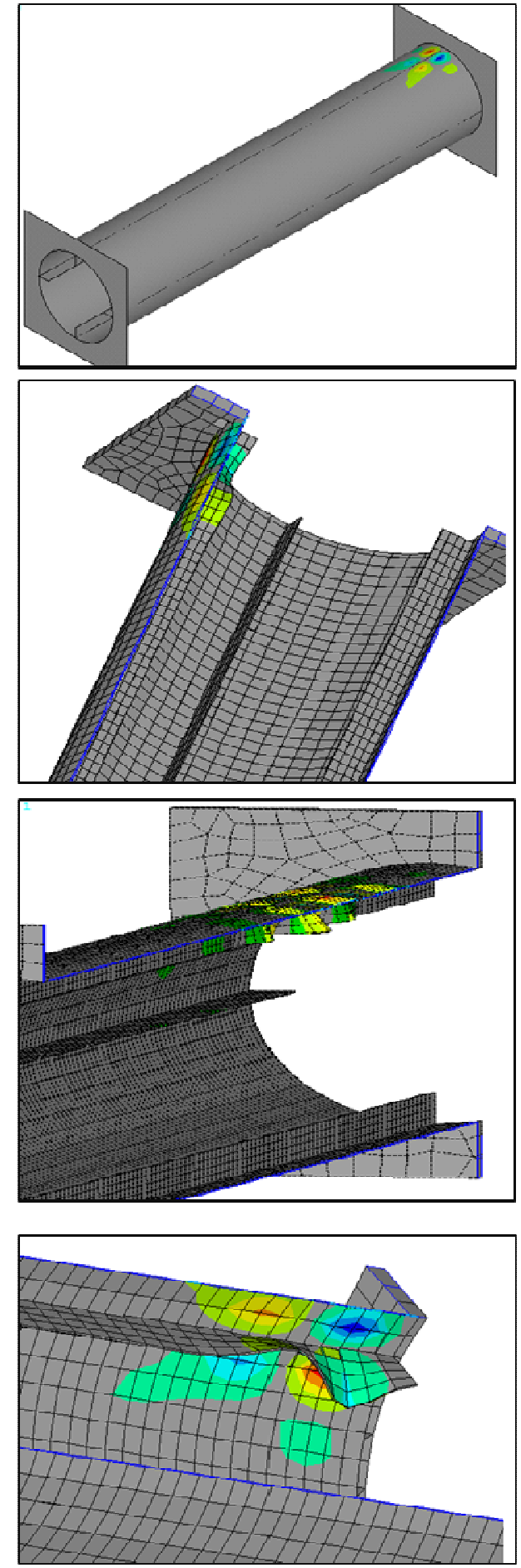

Fig. 6. Loacal buckling of four stiffneres 

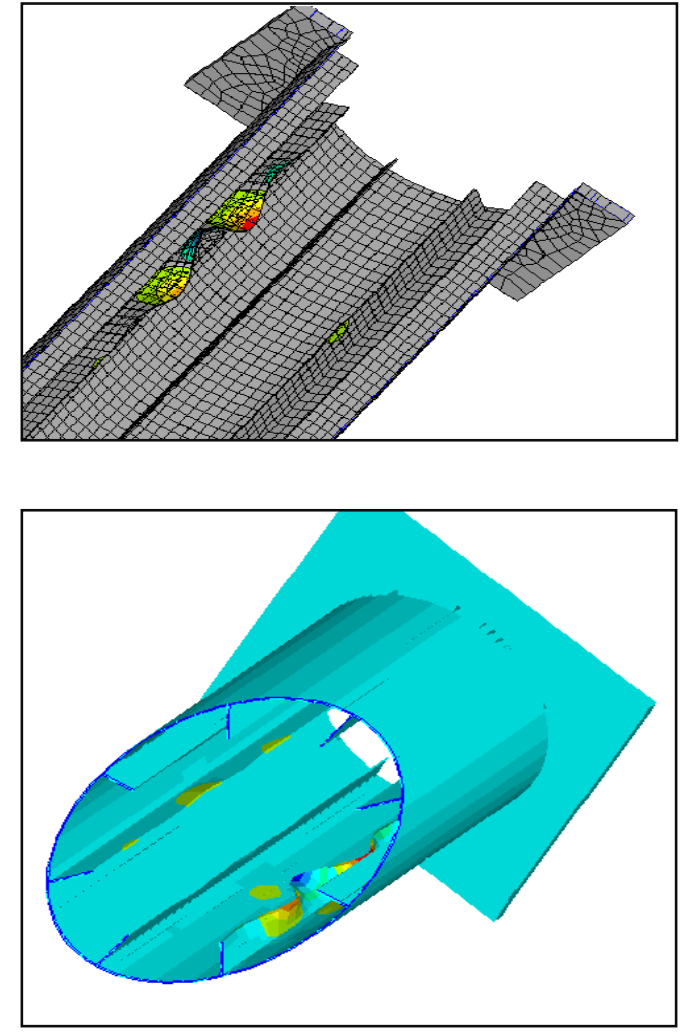

a- 8 stiffeners
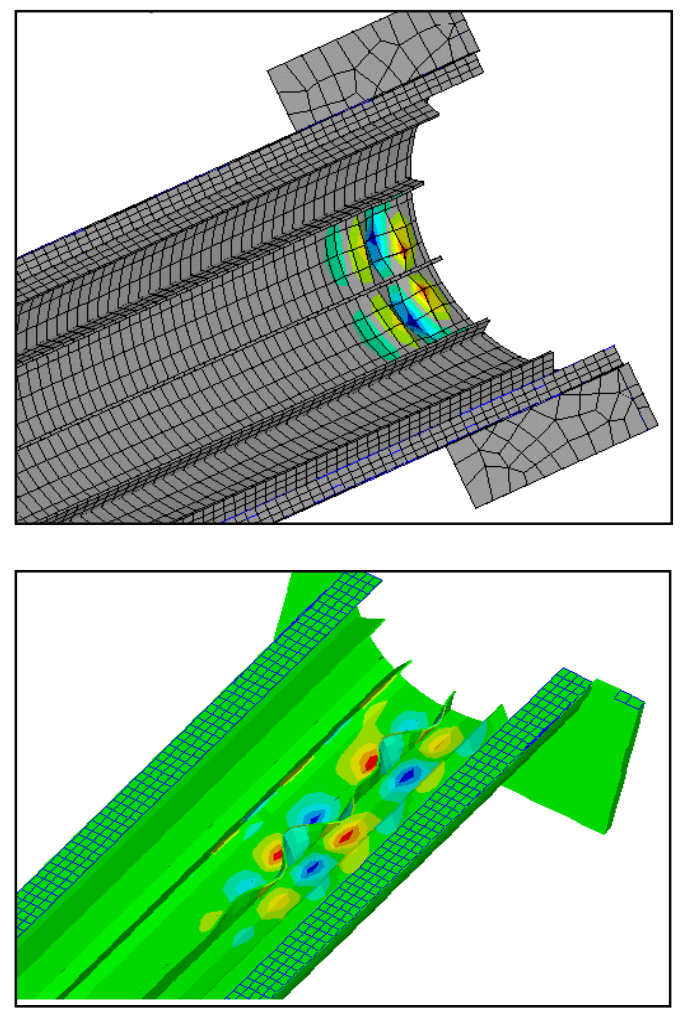

b- 12 stiffeners

Fig.7. (8 and 12) stiffeners with different $h / t$ s.

\subsection{Taguchi and ANOVA Results}

The orthogonal array is shown in Table 4 , while the results of mean based on $\mathrm{S} / \mathrm{N}$ were presented in Table 5 and Fig. 8.

Table 4,

Orthogonal array and S/N

\begin{tabular}{|c|c|c|c|c|c|}
\hline $\begin{array}{l}\text { No. } \\
\text { of } \\
\text { tests }\end{array}$ & $\begin{array}{l}-\mathrm{A}- \\
\mathrm{N}_{\mathrm{s}}\end{array}$ & $\begin{array}{l}-B- \\
h / t_{s}\end{array}$ & $\begin{array}{l}-C- \\
D / t\end{array}$ & $\begin{array}{l}\text { Critical } \\
\text { Buckling } \\
\text { Load } \\
\text { MN }\end{array}$ & $\mathbf{S} / \mathbf{N}$ \\
\hline 1 & 4 & 25 & 400 & 34.52 & 30.761 \\
\hline 2 & 8 & 25 & 400 & 37.78 & 31.545 \\
\hline 3 & 12 & 25 & 400 & 40.28 & 32.102 \\
\hline 4 & 4 & 6.25 & 400 & 42.72 & 32.613 \\
\hline 5 & 8 & 6.25 & 400 & 44.78 & 33.022 \\
\hline 6 & 12 & 6.25 & 400 & 49.82 & 33.948 \\
\hline 7 & 4 & 1.6 & 400 & 45.28 & 33.118 \\
\hline 8 & 8 & 1.6 & 400 & 48.55 & 33.724 \\
\hline 9 & 12 & 1.6 & 400 & 50.37 & 34.043 \\
\hline 10 & 4 & 25 & 200 & 76.63 & 37.688 \\
\hline 11 & 8 & 25 & 200 & 77.86 & 37.826 \\
\hline 12 & 12 & 25 & 200 & 80.22 & 38.086 \\
\hline 13 & 4 & 6.25 & 200 & 137.58 & 42.771 \\
\hline 14 & 8 & 6.25 & 200 & 140.79 & 42.971 \\
\hline 15 & 12 & 6.25 & 200 & 159.83 & 44.073 \\
\hline 16 & 4 & 1.6 & 200 & 147.53 & 43.378 \\
\hline 17 & 8 & 1.6 & 200 & 150.01 & 43.522 \\
\hline 18 & 12 & 1.6 & 200 & 161.51 & 44.164 \\
\hline 19 & 4 & 25 & 133 & 113.51 & 41.101 \\
\hline 20 & 8 & 25 & 133 & 115.18 & 41.228 \\
\hline 21 & 12 & 25 & 133 & 118.06 & 41.442 \\
\hline 22 & 4 & 6.25 & 133 & 319.47 & 50.089 \\
\hline 23 & 8 & 6.25 & 133 & 327.52 & 50.305 \\
\hline 24 & 12 & 6.25 & 133 & 334.82 & 50.496 \\
\hline 25 & 4 & 1.6 & 133 & 332.11 & 50.426 \\
\hline 26 & 8 & 1.6 & 133 & 339.27 & 50.611 \\
\hline 27 & 12 & 1.6 & 133 & 343.14 & 50.709 \\
\hline
\end{tabular}

From the Table 5 and Figure 8 it is seen that the optimum set of levels is (A3 B3 C3) which gives the best critical buckling load. This means that the Number of stiffeners is 12 and the $(\mathrm{h} / \mathrm{ts}$ $=1.6)$ and $(D / t=133)$. Delta column represents the difference between the highest and lowest level 
value. It indicates that the ratio $\mathrm{D} / \mathrm{t}$ (cylinder thickness) has more effect than the other parameters.

Table 5,

Analysis of mean results based on $\mathrm{S} / \mathrm{N}$

\begin{tabular}{|c|c|c|c|c|c|c|}
\hline 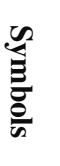 & 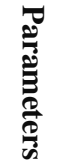 & $\begin{array}{l}\frac{5}{2} \\
\frac{2}{2} \\
-1\end{array}$ & 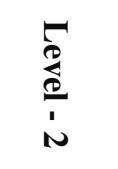 & 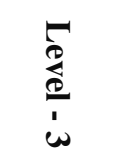 & $\underset{D}{\stackrel{D}{*}}$ & 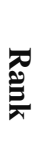 \\
\hline $\mathbf{A}$ & $\mathbf{N}_{\mathrm{s}}$ & 40.216 & 40.528 & 41.007 & 0.791 & 3 \\
\hline B & $\mathbf{h} / \mathbf{t}_{\mathrm{s}}$ & 36.864 & 42.254 & 42.633 & 5.769 & 2 \\
\hline C & $\mathrm{D} / \mathrm{t}$ & 32.764 & 41.609 & 47.379 & 14.62 & 1 \\
\hline
\end{tabular}

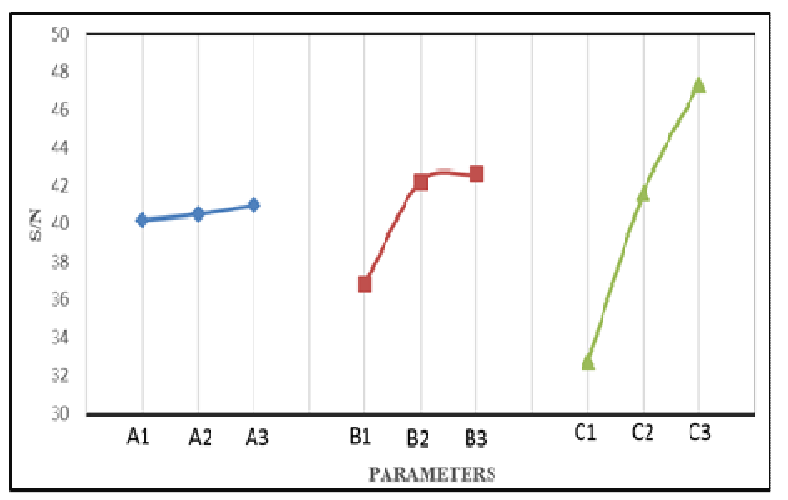

Fig. 8. The parameters- $\mathrm{S} / \mathrm{N}$ curves

Table 6 shows the results of ANOVA. These results indicate the importance and contribution of parameters as a percentage. The $\mathrm{D} / \mathrm{t}$ ratio has the highest contribution (80.814\%) and the lowest and approximately no effect is number of stiffeners $(0.133 \%)$.

Table 6,

ANOVA result

\begin{tabular}{llllll}
\hline Source & Sum sq. & d.o.f & $\begin{array}{l}\text { Mean } \\
\text { sq. }\end{array}$ & F & P \% \\
\hline A & 1.67 & 2 & 0.834 & 0.33 & 0.133 \\
B & 188.45 & 2 & 94.225 & 37.15 & 15.02 \\
C & 1014.21 & 2 & 507.10 & 199.9 & 80.81 \\
Error & 50.73 & 20 & 2.536 & & 4.042 \\
Total & 1255 & 26 & & & \\
\hline
\end{tabular}

\section{Conclusion}

This paper has presented the analysis of linear buckling which results from pure bending. In this work, the bending was applied on hollow cylindrical thin walled structure strengthen by longitudinal stiffeners. The finite elements methods used to carry on the analysis. It was shown that the thickness of the cylinder is more effective parameter on the critical buckling load which is followed by the shape of cross section for stiffeners. The results indicated that the number of stiffeners shows approximately no effect to the critical load of buckling. These results approved and conformed by using the Taguchi and ANOVA methods. Taguchi gaves the weight of parameters and the best-set combination of parameters, while ANOVA showed the percentage of contribution for each parameter. The results demonstrated that Taguchi and ANOVA are power full tool to investigate the importance of parameters during the design of structures.

\section{References}

[1]L. Guo, S. Yang, and H. Jiao, "Behavior of thin-walled circular hollow section tubes subjected to bending," Thin-Walled Struct., vol. 73, pp. 281-289, 2013.

[2]T. P. Peterson, "Bending Tests of Ring Stiffened Circular Cylinders," 1956.

[3] J. Singer, "The Influence of Stiffener Geometry and Spacing on the Buckling of Axially Compressed Cylinderical and Conical Shells," Technion-Israel Institute of Technology, 1967.

[4]N. T. Phuong and D. H. Bich, "Buckling analysis of eccentrically stiffened functionally graded circular cylindrical thin shells under mechanical load," vol. 29 , no. 2, pp. 55-72, 2013.

[5]D. Huy, D. Van Dung, V. Hoai, and N. Thi, "Nonlinear static and dynamic buckling analysis of imperfect eccentrically stiffened functionally graded circular cylindrical thin shells under axial compression," Int. J. Mech. Sci., vol. 74, pp. 190-200, 2013.

[6] M. Shariati and A. Akbarpour, "Buckling and Post Buckling Investigation of Thin Walled Shells Contain Elliptical and Circular Cutout, Subjected to Oblique Loading," vol. 2, no. 9, pp. 9548-9557, 2012.

[7] C. A. Dimopoulos and C. J. Gantes, "ThinWalled Structures Experimental investigation of buckling of wind turbine tower cylindrical shells with opening and stiffening under bending," Thin Walled Struct., vol. 54, pp. 140-155, 2012. 
[8]H. Reyno, J. Park, and Y. Kang, "Influence of Door Opening and Collar Stiffener on the Buckling Capacity of Cylindrical Wind Tower," vol. 8, no. October, pp. 1-7, 2015.

[9]B. D. Reddy, "An Experimental Study of The Plastic Buckling of Circular Cylinders in Pure Bending," Int. J. Solids Struct., vol. 12, pp. 669-683, 1979.

[10] H. Jiao and X. L. Zhao, "Section slenderness limits of very high strength circular steel tubes in bending," Thin-Walled Struct., vol. 42, no. 9, pp. 1257-1271, 2004.

[11] P. C. Khonke and W. C. Schnobrich, "A Finite Element Analysis of Eccentrically Stiffened Ciruclar Cylindrical Shells," Urbana, Illinois, 1969.

[12] S. E. Kim and C. S. Kim, "Buckling strength of the cylindrical shell and tank subjected to axially compressive loads," Thin-Walled Struct., vol. 40, no. 4, pp. 329-353, 2002.

[13] N. N. Thakre and D. V Bhope, "Investigation of Stresses in Ring Stiffened Circular Cylinder," no. 9, pp. 97-101, 2014.

[14] A. T. Tran, M. Veljkovic, and C. Rebelo, "Buckling Observation of Door Openings for Wind Turbine Towers," no. September, pp. 4-11, 2015.

[15] V. Polenta, S. D. Garvey, D. Chronopoulos, A. C. Long, and H. P. Morvan, "Optimal internal pressurisation of cylindrical shells for maximising their critical bending load," Thin-Walled Struct., vol. 87, pp. 133-138, 2015.

[16] L. Gangadhar and T. S. Kumar, "Finite Element Buckling Analysis of Composite Cylindrical Shell with Cutouts Subjected to Axial Compression," vol. 89, pp. 45-52, 2016.

[17] O. Lykhachova, "Numerical Simulation of Axially Compressed Cylindrical Shells with Circular Cutouts," vol. 20, no. 3, pp. 309320, 2016.
[18] A. Khamlichi, J. El Bahaoui, L. El Bakkali, M. Bezzazi, and A. Limam, "Effect of Two Interacting Localized Defects on the Critical Load for Thin Cylindrical Shells Under Axial Compression," Am. J. Eng. Appl. Sci., vol. 3, no. 2, pp. 464-469, 2010.

[19] A. Khamlichi and A. Limam, "Assessing the Effect of Two Entering Triangular Initial Geometric Imperfections on the Buckling Strength of an Axisymmetric Shell subjected to Uniform Axial Compression," in Proceedings of the Eleventh International Conference on Computational Sructures Technology, 2012, pp. 1-11.

[20] R. D. Cook, Finite Element Modeling for Stress Analysis. New York: John Willy and Sons, Inc., 1995.

[21] A. H. Suri, "A study of structure stability using the finite element method and minimum weight design of composite panel," University of Glasgow, 1983.

[22] M. S. Phadke, "Quality Engineering Using Robust Design.” P T R Pentice Hall, Englewood Cliffs, New Jersey, 1989.

[23] J. Lin and K. Lee, "Optimization of Bending Process Parameters for Seamless Tubes Using Taguchi Method and Finite Element Method," Adv. Mater. Eng., vol. 2015, 2015.

[24] Rupert G. Miller, "Beyond ANOVA, Basics of Applied Statistics." John Wiley \& Sons, Inc., Canada, 1986.

[25] L. Jiang, Y. Wang, and X. Wang, "Buckling analysis of stiffened circular cylindrical panels using differential quadrature element method," Thin-Walled Struct., vol. 46, no. 4, pp. 390-398, 2008. 


\title{
المستوى الافضل لحمولة الالتواء الحرج لهيكل رقيق الجدران دائري معرض للانحناء
}

\author{
口سين محمد $\square$

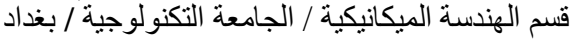 \\ hussalkhafaji@gmail.com : البريد الالكتروني
}

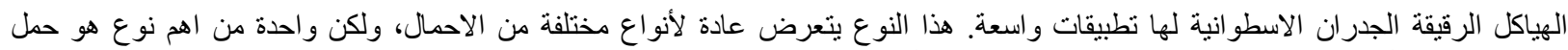

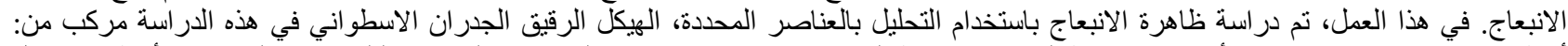

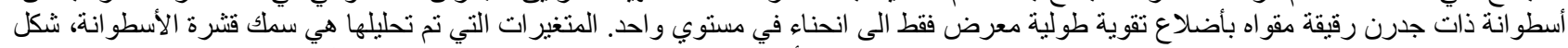

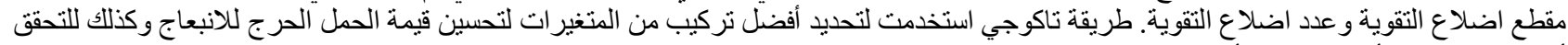

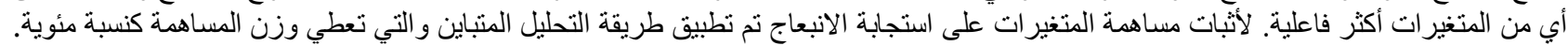

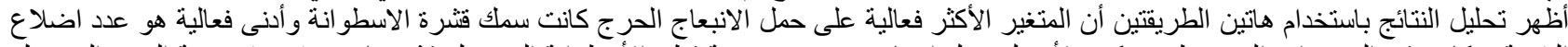

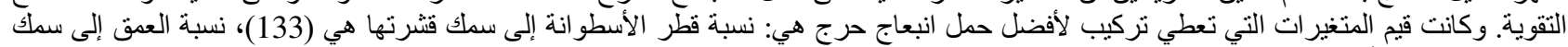

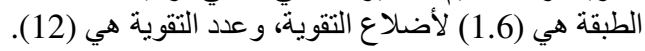

